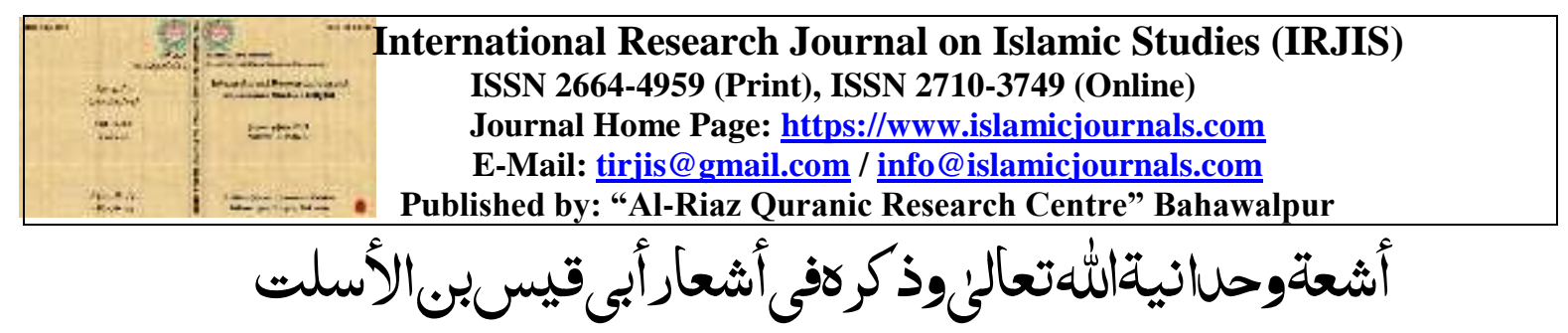

The Rays of the Oneness of God Almighty and His Remembrance in the Poems of Abu Qais Bin Al Aslat

\title{
Ayesha Tahreem,
}

Ph. D Scholar (Arabic),

Email: ayeshatareem907@gmail.com

ORCID ID: https://orcid.org/0000-0002-4771-5658

To cite this article: Ayesha Tahreem. 2021. "The Rays of the Oneness of God Almighty and His Remembrance in the Poems of Abu Qais Bin Al Aslat". International Research Journal on Islamic Studies (IRJIS) 3 (Issue 2), 18-33.

Journal:

Publisher:

URL:

DOI:

Journal Homepage

Published:

License:

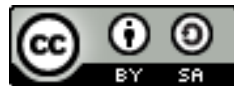

International Research Journal on Islamic Studies

Vol. No. 3 || July - December 2021 || P. 18-33

Al-Riaz Quranic Research Centre, Bahawalpur

https://www.islamicjournals.com/arabic-3-2-2/

https://doi.org/10.54262/irjis.03.02.a02

www.islamicjournals.com \& www.islamicjournals.com/ojs

December $31^{\text {st }}, 2021$

This work is licensed under an

Attribution-ShareAlike 4.0 International (CC BY-SA 4.0)

\section{Abstract:}

In this article, it has been endeavored to analyze the Oneness of Allah mentioned in the lines of Abu Qais Bin Al-Aslat. His name was Amer Bin Jashm bin Malik, and it was said Al Harith, and as for Al Aslat, it was his father's title. He was a great poet from the poets of Al-Auos Jahiliyyah, as Ibn Salam Al Jamhi considered him one of the stallions of poetry AlMadinah Al-Five. He was wise and of good opinion and led his people in the war. He thought that who ran away from Moses, and the Lord of perfect servants, who is like that? So, he said: "The Lord of the servants is the God of Moses. This poetry indicates uniformity in four aspects because the expression Lord, the servants, the god of Moses, and to avoid the difficult, etc.". Each of them denotes monotheism and its detail. This is because the Lord is the self who grows and raises everything and increases it day by day until he reaches him to his intended home. In short, that monotheism was an ignorant poetic topic. Abu Qais bin Al Aslat Al Auosi was from Al Hanafi. His knowledge of religious issues was wide and wide. The remainder of himself, his qualities, and the belongings of his qualities were transmitted in the Jahili Arabs. That your solution to polytheism on God and his family does not determine the lights of monotheism. 
Keywords: analyze, oneness, stallions of poetry, lines, jahilya poetry, monotheism, polytheism.

حين ما نتكلم أو نسمح لفظ ” الجاهلية ، فتأتى بسرعة فى أذهاننا اشبا ح شتّى ونتجول فى افكارنا الغريبة ،ونستغرق فى الأبحار العهيقة ونستقيم الهروضات ثم نحكم عليهم بأنهم كانوا وحثيّّ وهم كانوا مجرّدين عن الخلق الفاضلةوعارين عن الأفعال الهادحة والأقوال الصادقة والأعهال الحسنة. وكم من الخطباء والقصاص أنهم ين كروث بحناجر مفتوحة أن أهل عصر الجاهلية كانوا يرتكبون الكبائرويأثهونويحرمونويقضون حياتهم كلها فى معصية اللهوعلوانه،و كلهم يسقطون على القوافل الر احلة ويغتصبون منهم البضائح والسلّة ويبيتون لياليهم فى شرب الثراب وأخن السكر واستهت] ع الأغنية ويأكل بعضهم بعضا ويئلون بناتهم ولا ين كرون الله ولايؤمنون بألله ولابلآخر وغيرذالك من الكلام العجيبة والخريبة

لامرية فيه أنبعض الجر ائم بل الجر ائم الكبرى قلصررت عنهم ولكى الحكم على الكل أوعلى جهيح الهجتهات ليس بصحيح كاقال الحريرى:

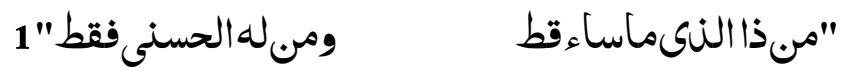

لان الفطرة التى خلقها الله تلعى الى الوحانيةوالعقل الصحيح تضطر الى الايهان باللهلوحلهـ فاذا نرى هناك شخصيات صغت قلوبهم الى اظهار التوحيلو الربوبيةونجلفيهم شرذمة معترفيت بالربوبية والوحسانية

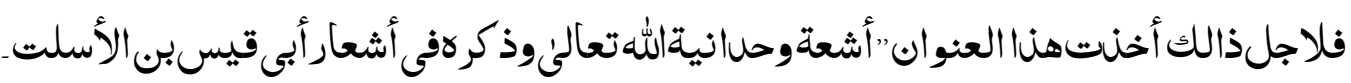
2

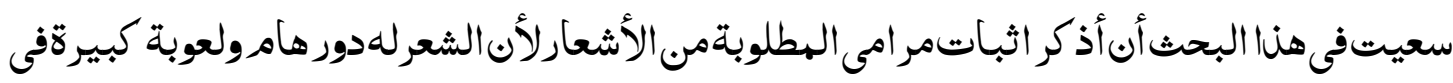
بيئة مأوعلى الأخصفى البيئة العربيةوتاريخهمهلوءةوضليعةبإلشعرفلنا يقال "انبابُأمّة الشعرو الثعرديوان العرب"

وعلى العموه قل امتلأت منطقة العرب كلها بالثعر ولكن يثرب (الهلينة الهنورة )بعل الهجرة النبى عليه السلامر،فالهنا القول؛ يكفى لنا شهادةابنسلاهم الجمحى التى دالّةعلى تقدمهاوتفوقها فقال:

1 Al Hariri, Abu Muhammad Qasim ibn Ali ibn Uthman, (d. 516 AH), Maqamat E Hariri، Maktaba Dar Ul Turath, Cairo, P. 53

2- Muhammad Aboul Fotouh Ghoneim, Definition of Poetry, Its Usefulness, Virtue and Its Elements, AlWatan Newspaper, Publication Date, 05-13-2009 


$$
\text { "اشعرهنقرية الهلينة" }
$$

ولكى دأب الهناطق الاخرى' ولقرى نظن ان اشعار هنه القرية وأعمالها الشعرية كانت متخنة ومستقيهة على الفخر القبلى والحاسةوالشجاعةوالحربوغيرهامى الهوضوعات الأخرىوهى خطأفادح. ولكن مح الأسف العنيف حين ما نتكلم حول الشعر الجاهليين وأعهالهم الشعرية نبحث من ناحية

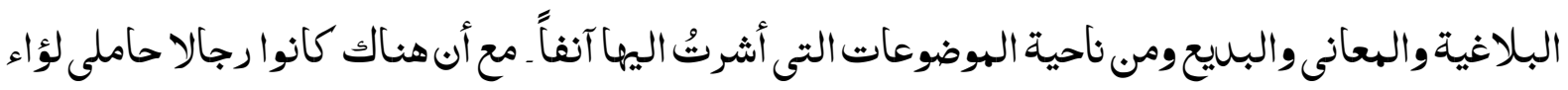
التوحيu ورافحى رأى الوحانية بالله تعالى فى البيئة الهظلمة والهحاشرة الحلك كها صرح ذالك الثاة ولى الله السهلوى:

$$
\text { "ليست كانت قريةفى العربالاوجلفيهارجال الهؤحلون" - } 4
$$

فكنالك توجلفى قرى يثربشخصياتوشعر آءذا التوحيلو الوحانيةبالله ـومىشعر آثما الشامخة أبوقيسبن

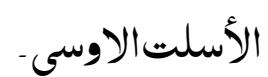

$$
3
$$

أبوقيس بن الاسلت الأوسى وكان اسهه عامر بن جشه بن مالك ،وقيل صيفى ،وقيل الحارث واما

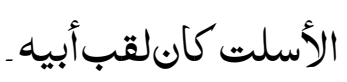

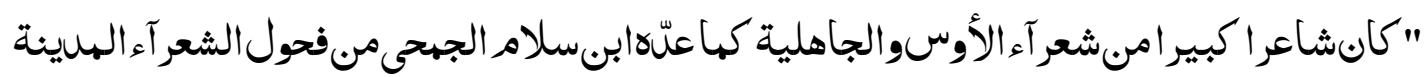

$$
5
$$

"و كانحكيها سليسالر أىوقادقومهفى الحرب" "بعاث" النَى غلبفيه الأوسعلى الخزرج". 6

أولاده:

$$
\begin{aligned}
& \text { "مـ أبنائهعقبةبنبنى قيس صحابي النىىاستثهليومر الوقادسيه" . }
\end{aligned}
$$

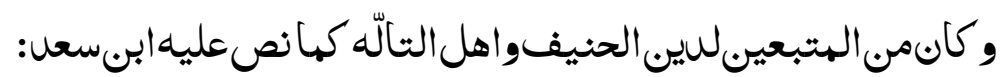

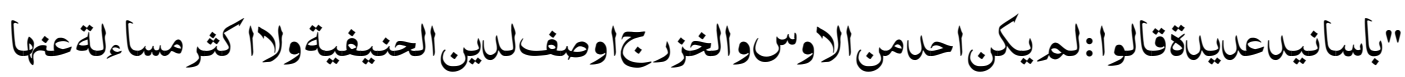

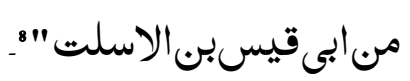

3- Ibn e Salam, Muhammad Bin Salam Al Jumahi, Tabaqat Al Shu`ara, Dar Al Kutub Al Ilmiyya, Beirut, P. 87

4- $\quad$ Shah Wali Allah, Hujjat Allah Al Baligha, Maktaba Rashidiya, Peshawar, Pakistan, Vol. 1, P. 277.

5- $\quad$ Ibn Salam, Muhammad Bin Salam Al Jumahi, Tabaqat Al Shu`ara’, P. 88

6- Ibn Hisham, Abd Al Malik Bin Hisham Al Himyari, Al Seerat Ul Nabaviyyah, Dar Ul Maarifa, Beirut, $20 / 2$

7. Al Maqdisi, Ibn Qudamah, Al Istibsar Fi Nasb Al Sahabah Min Al Ansar, Dar Ul Fikr, Beirut, 1972, P. 274

8 ibn Sa'd 'Abū 'Abd Allāh Muḥammad ibn Sa'd ibn Man̄̄' al-Bașrī al-Hāshimī, Al Tabaqat Al Kubra, Investigation, Ali Muhammad Omar, Maktaba Al Khanji, Cairo, 2001, 7/277 
وهكنا لها اعتهر فكلّم زيuاً بب عمروبن نفيلٍ فكان عنه يقول:" ليس احل على ديث ابرهيم الا انا وزيس بن فهروبن نفيلٍ" -.

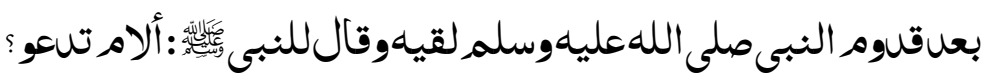

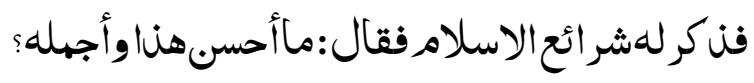
ثم لقيهعبuاللهبب ابىبنسلول في الطريقفقال:

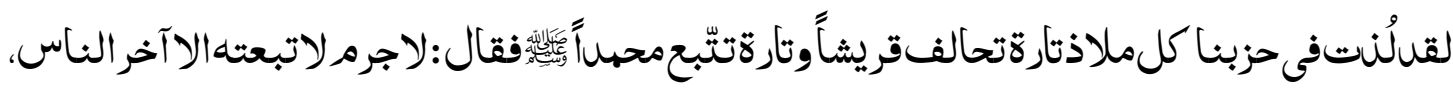

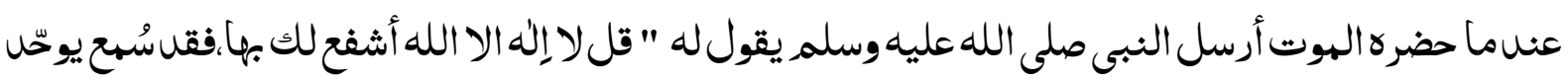
عنسالهوت". وفىرواية ابن البكار انهلم يؤمن على النبى صلى الله عليهوسلم بل قال لابى بن ابى سلول: لآمب عليه

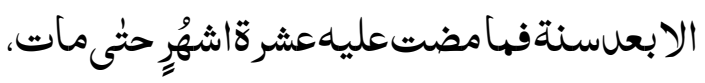

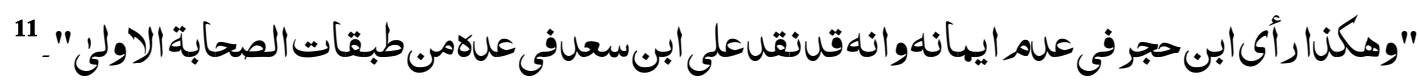
مثلهنهالهسئلةآراءمتشاجرةافى وفاتهقال ابن عساكر : "توفى فى السنة الاولى من الهجرة وانهمكث حياً ألى فتح الهكة". 12

فالحاصل انه على ايّة حالة كان ؟ ان لم يؤمن ويسلم على دين الله وشريعته ولكن كان يحب التوحيu

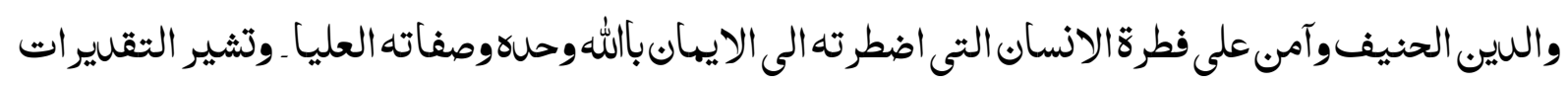
إلى أنه اعتنق الإسلاه لكن وفاته فى السنة الأولى للهجرة لم. تجعل إسلامه يحظى بالشعبية ـله تن كر أفكار الجاهليةفى قصائنأبى قيس بن الاصلت بعلظهور الإسلام فى الهليئة الهنورة.

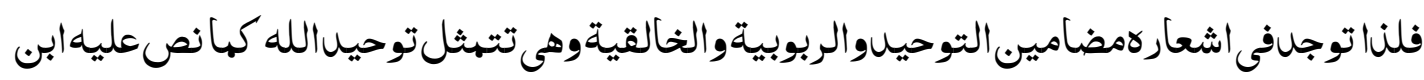
سعلقبلُ آنفاً ولنا اشعاركاذوقيهة وثهينة وتتهثلتوحيناللهكها سيبرزفى الأشعار الآتية.

9. $\quad$ Ibid., 7/278

10- Ibn Sa'd, Muhammad Bin Sa'd, Al Tabaqat AlKubra, 7/277

11- Al i, Abdullah, Al Wafi Bil Wafiyyat, Dar Ehya Ul Turas, Beirut, 2000 AD, 16/299

12- Ibn Asaker, Tareekh Madeenat Damishq, Dar Ul Fikr, Beirut, 24/247 
4

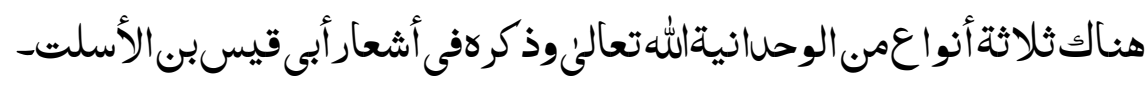

$$
\begin{aligned}
& \text { 1 } \\
& \text { 2: } \\
& \text { 3: : } \\
& \text { أشعاركفى التوحيuبالنات: }
\end{aligned}
$$

1:

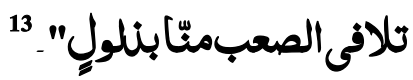

$$
\text { "ربالعبادرالهموسن }
$$

$$
\text { هنا الثعر يuل على التوحيلباربعة اوجُه: }
$$

لان لفظ " رب ،العباد ،اله موسنى و تلافى الصعب الخ " كل منها تسل على التوحيu وتفصليه هنا لاث

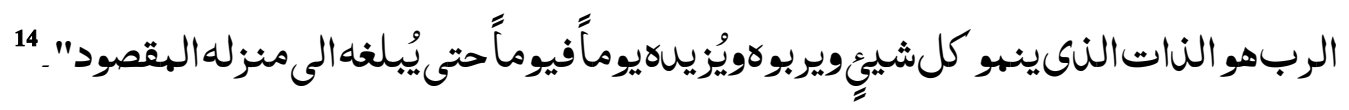

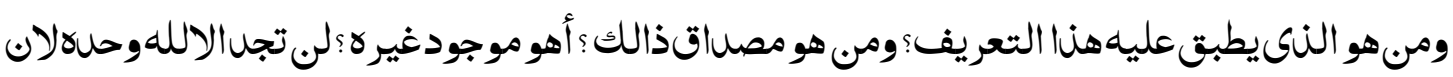

$$
\text { لفظ "الرب" تستخلصم لنات تفوق كلشىوتعرفباسم الله" . } 15
$$

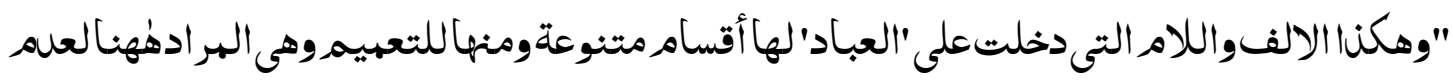

$$
\text { قرينة مانعة أوحاجزةامنها]" - } 16
$$

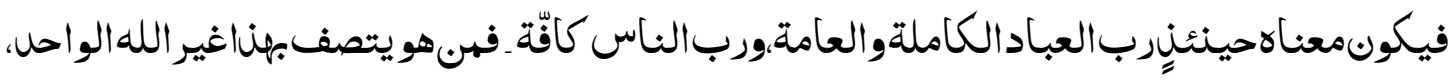

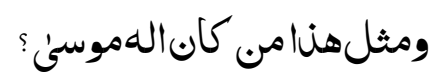

$$
\text { ومن كانبيعبلاموسني ماسوى اللهالرحمن؟ }
$$

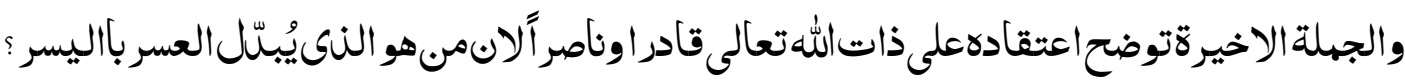

$$
\begin{aligned}
& \text { ومن لهطاقة يتغير بها الحكالات اليومية؟ } \\
& \text { ومب لفباعةيتلافى بها الصحب الهشكلاتبسهلٍ } \\
& \text { فكل ذرّةتمب العالمـو الفضاء تثهلعلى وحسانية الله تعالى. }
\end{aligned}
$$

13- Bajodah, Dr., Hassan Muhammad,Diwan-E- Abi Qais Bin Al Aslat, Maktaba Dar Ul Turath,Al Qahirah ,Egypt, P. 87

14- Al-Baydawi, Nassir Ul Din Al Shirazi, Anwar Al Taweel and Asrar Al Taweel, Dar Ul Kutub Al Ilmiyya, Beirut, P. 07

15- Al Africi, Ibn Manzor, Lisan Ul Arab, Dar Ul Maarifa, Cairo, 1/399

16- Al Zujaji, Abu Ul Qasim Abd Ul Rehman, Kitab Ul Lammat, Edited by Maren Mubarak, Dar Ul Fikr, Damascus, P. 42 
وان الشاعر لم يفهم الله تعالى رب العباد الكاملة فقط بل كان يعتقل انه منبح الخير ومصرر الهاية

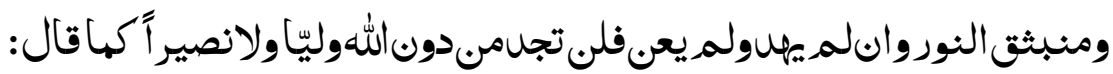

فيسوقنالهعروفالسبيل". - 17 "ربالعبادامإذاضلنلا

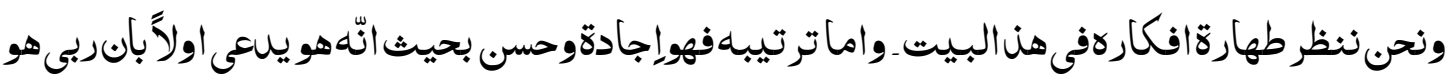
ربالعبادالعامروكافةإنأريسباللاهـ لاهـ الاستغراق.

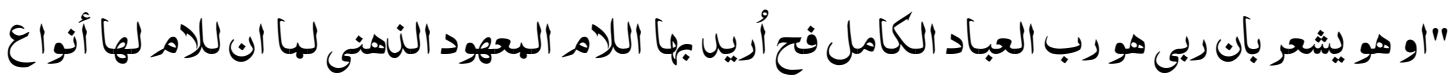

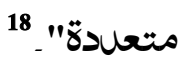

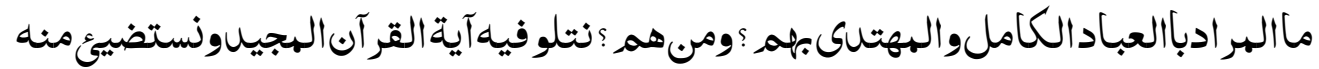
"اُولئك النين هلىى اللهفبهناهم اقتله". . 19

"وهم جهاعة الانبياء الهقسة ثم عقب الليل عليهفقال :امّا اذوهـامن حروف الشرطوالجزآءمتى والضلالةعلى راى الجرجانى :

"هى فقلانما يوصل الى الهطلوبوقيلهى سلوكلا يوصل الى الهطلوب".. 21

وهى تحيط بجديح انواعها الضلالة الفكرية، الضلالة النهنية، الضلالة السينيةوالنيوية، فيكون معناه

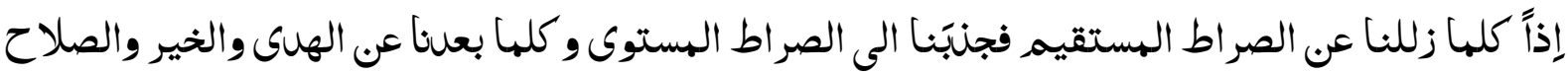

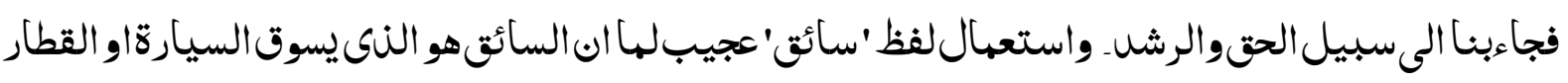
ونتوهنا.

كها نعلم ان الركابليس لهم لعوبة في اجر اء الهركب كنالك ان الله تبارك وتعالئيقودهم ويسوقهم

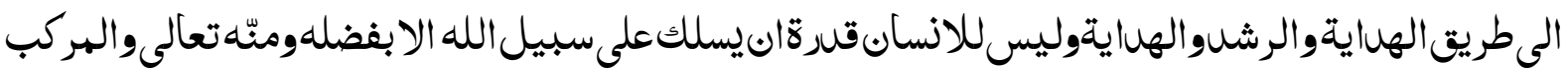
والسيارةوهى دين الحنيف كهاسيتضحفى الاشعار الآتيةبعنُ

17. Diwan-E- Abi Qais Bin Al Aslat, P. 87

18- Al Zujaji, Abu Ul Qasim Abd Ul Rehman, Kitab Ul Lammat, P. 42

19. Al Anaam: 6/90

20- Al Bayani, Zaher Shaukat, Adawaat Ul Aarab, Majd Al Muasasah Al Jamia Linashar Wal Dirasaat, Beirut, P. 220

21- Al Jurjani, Al Sayyid Sharif, Al Tareefat, Investigation, Muhammad Siddiq Al Minshawi, Dar Al Fazilah Linashar Wa Al Tuzeekh, Cairo, P. 117

22- Majmae Ul Lughat Ul Al Arabia, Al Muejim Al Waseet, Maktaba Al Shorouk Al Dauliyah, 2004, P. 438 


$$
\begin{aligned}
& \text { "وفى روايةفيَسّر نامحل يسوقن]" - } 23 \\
& \text { فاذا يكونمعنالهجعَلنا اسباباعرفنابهمعرفة اللهوقررته ـ }
\end{aligned}
$$

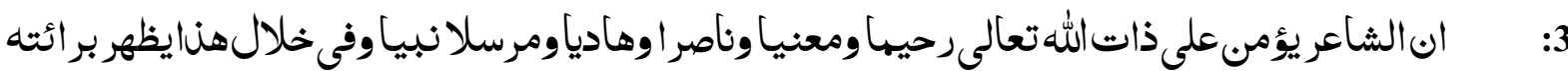

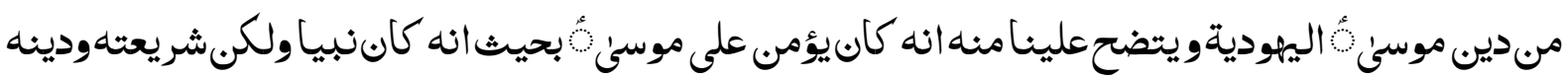
قلصارت محرفاومتغير اومتبللا فىشكوكو ابهاه عسياةفقال:

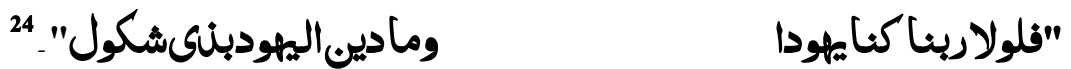

ان الثاعر يهلح الله ويثنى عليه انه اتّقاهم عن الغواية والضلالة وابعلهم عن السخيف وثياب

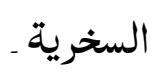

وهنا الثعرمثلشعرسيسناعبلاللهابثرواحةر ضى اللهعنه:

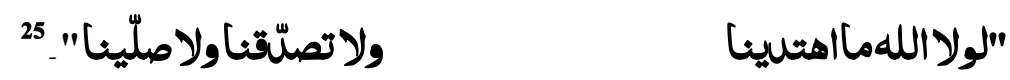

فقال : يألله !لولا انت لكنا اليوه على حالة غير قابلة للن كر والبيان،يكاد انبكون يهوديا وعلى دينهم.

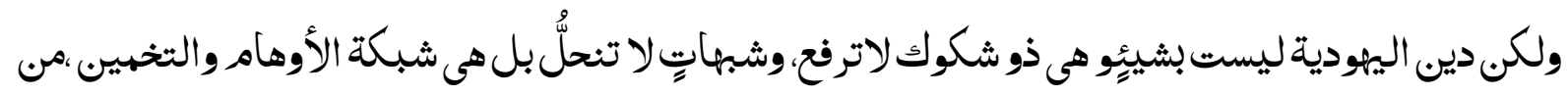
دخلفيها أحاطت بهكألاشو اكت

4: فيا الله لا يهكى الثناء عليك على فضلك العظيم ،ومنك الكبير ، كلما نريس ترك هنه الطريقة فجاءت

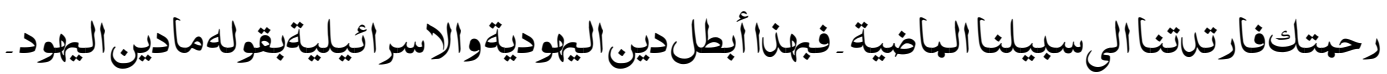
مثلذالك كانبؤمى على ذات اللهمنعها بحيث أبسىذالكبقوله

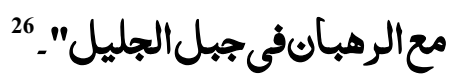

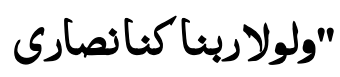

فقال : اثل له يك. الله معنا لكنا نصارى النين هم مجردون عن صلة الله ومحرومون عن تعلق الله ومتحيرون فى حصول الله ورحتنهوحائرون فى تعلى الله مرةًالى هنا واُخرى الى هناك حتى بلغوا اللى جبل الجيل مع انها أبعلمسافة وأكبر بعلاً كهانص عليهون الحهوى:

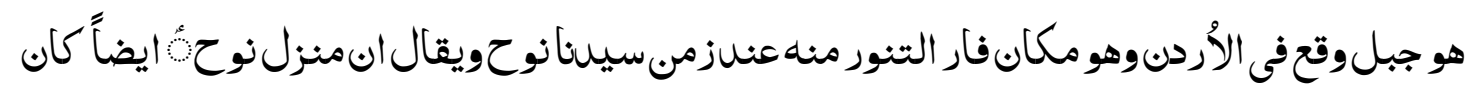

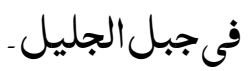


ثم ازداد : "هو جبل يقبل مب الحجاز فها كان بفلسطين فهو جبل الحهل وما كان بالالأردن فهو جبل

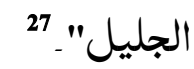
فثبت منه ايضا ان التوحيلدين الحضارة والارتقاء والتطويرلعلم ذهابه الى البلاد الاباعلة والقصوى

$$
\text { ولانحرف"لولا"تأتى لوجودالاولبنفى الثنىى". } 28
$$

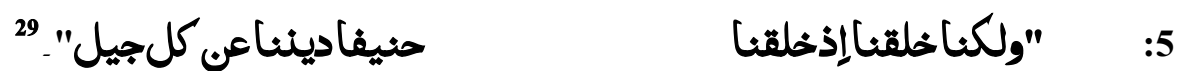

من خلقنا؛ وهو ليس بهن كور مح ان فى علاه ذكر الله تعالى مثلاً ذكر نسبة السوق والتلاقى الى الله

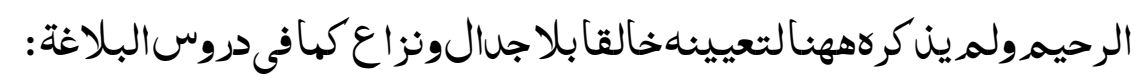

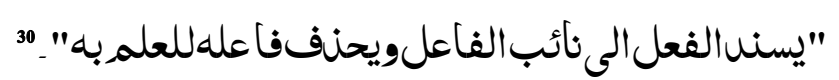

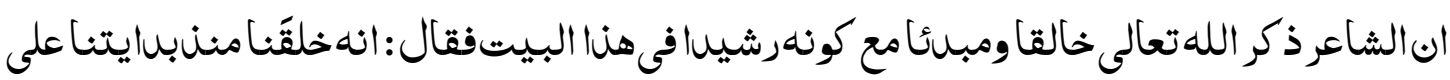

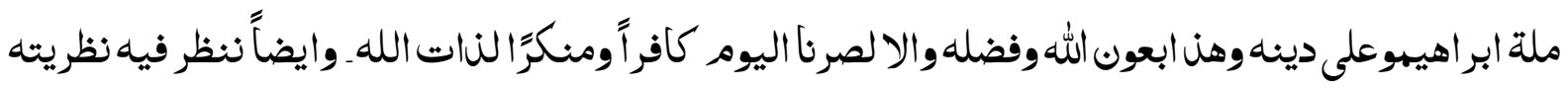

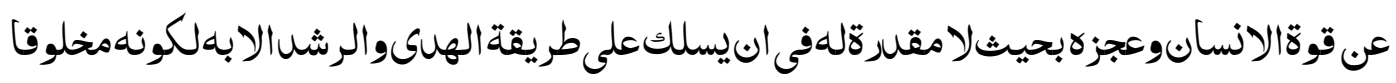

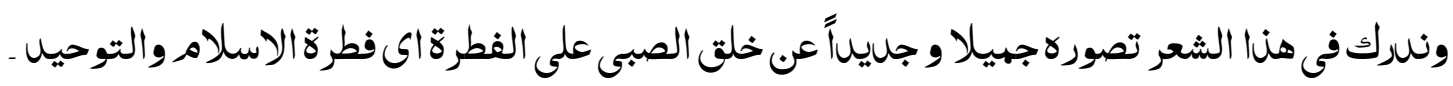

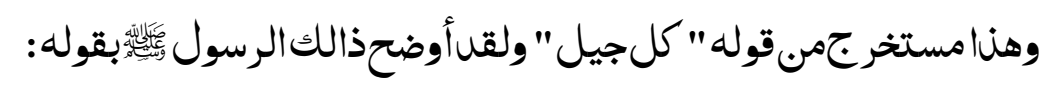

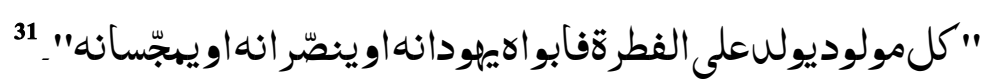

6: كنالك نجل انهم ماكانوا يعبلون الله تعالى بالعبادات القلبية أوالبنانية فقط بل بالعبادات الهالية

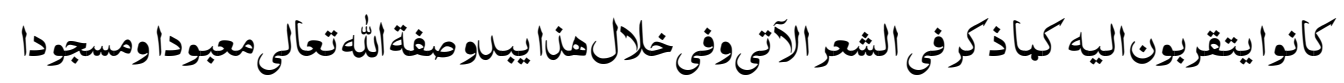

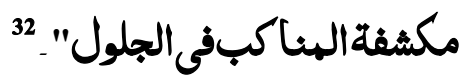

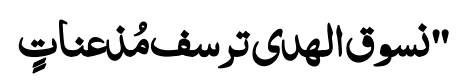

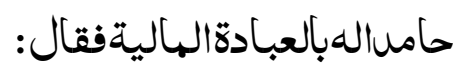

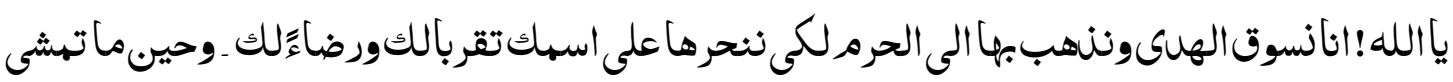
الناقات وغيرها الى جنابك القس فهى خاضعات اعناقهن لك وكاشفات مناكبهن فى السيار الاجنبية

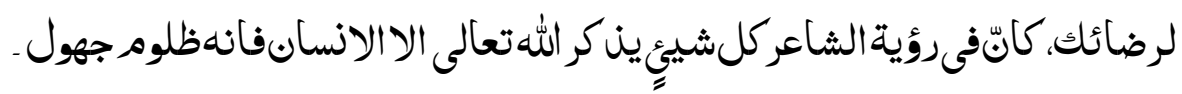

27- Al Hamawi, Yaqout Bin Abdullah, Mujam Al Buldan, Dar Al Sadir, 1993 AD, 2/158

28- Al Hamdani, Ibn Aqil, Sharh Ibn Aqeel Ali Alfiya Ibn Malik, Dar Al Turath, Cairo, 1980 AD, 1/249

29. Diwan-E- Abi Qais Bin Al Aslat, P.87

30- Hefni Bey Nasif, Daroos Ul Balagha, Maktaba Qassimia, Lahore, Pakistan, P. 41

31- Al Bukhari, Muhammad bin Ismail,Al Jamie Al Sahih, Hadith No.: 1385

32- Diwan-E- Abi Qais Bin Al Aslat, P.88 


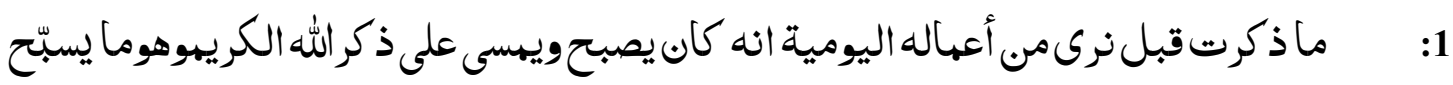

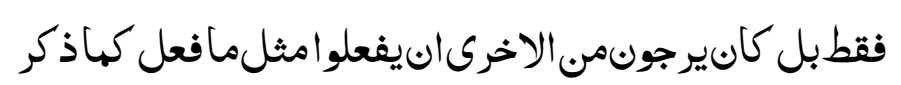

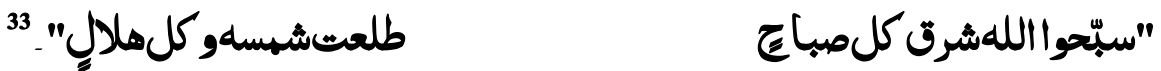

الشرق فى ضبطه لغتان، ،الشرقبسكون الر اء هو طلوع الشهس وذالكمن اسهاعها ايضاً وكنالك الشرَّق

$$
\text { بفتح الر اءوكلهلالِقُرءبالنصب عطفاً على الشرقببناء الظرفية الىوقت كلهلالٍ". } 34
$$

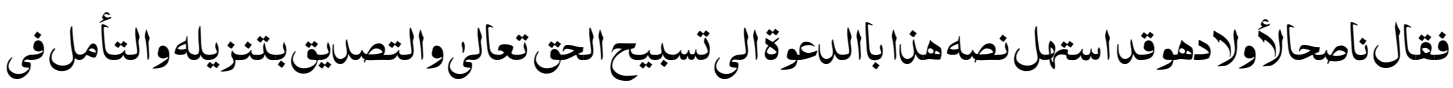

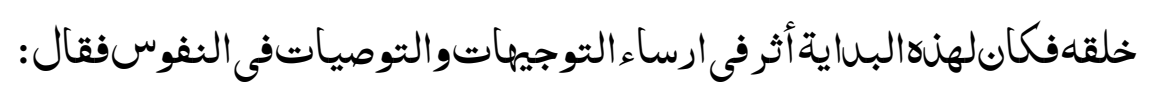

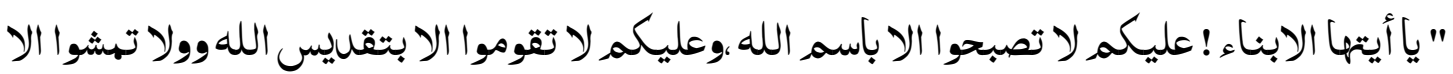

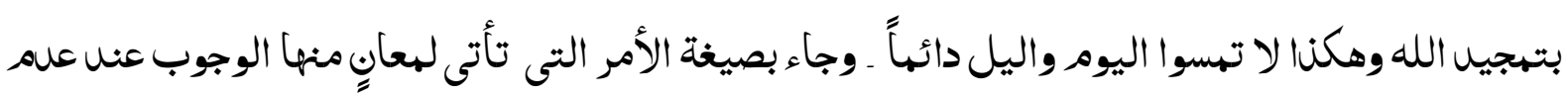

$$
\text { والقرينة". } 35
$$

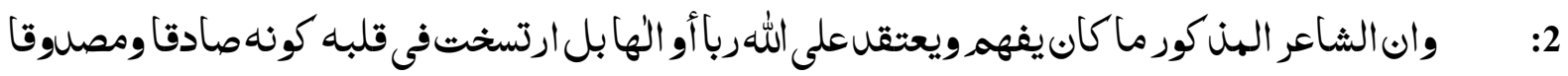
لكونهعالهاوخبير اوههالايكنبانفقال:

$$
\text { ليسماقتالربنابضلالٍ.. }
$$

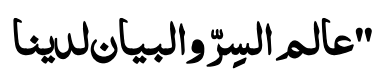

$$
\text { وهنا الشعريتضهن علىصفات آتية: }
$$

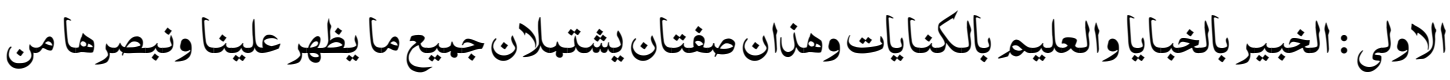

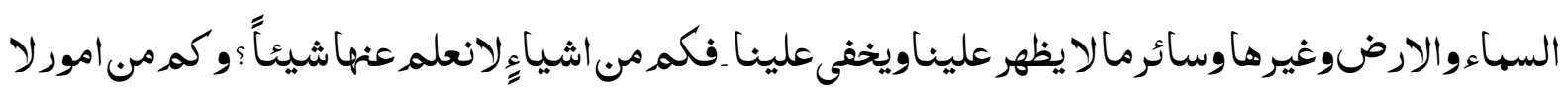

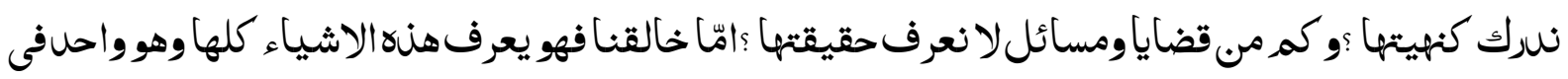
هنهالصفة. الثنانية : هى ان حليثه تعالئ وكلامهليس بكنوبٍ ولا بضلالة ولا يكاد ان يلغى كلامه فهى من نظافة

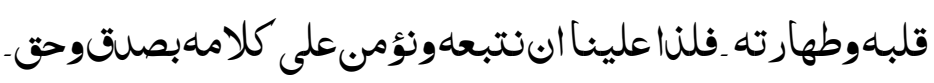

33- Diwan-E- Abi Qais Bin Al Aslat, P.85

34- Al Suhaili, Muhaddith Abd Al-Rahman, Al-Rauz Al-Anf, Investigator, Majdi Bin Mansour, Muhammad Ali Beydoun, Beirut, 2/362

35- Al Shashi, Nizamuddin, Osool Al-Shashi, Maktaba Haqqania, Multan, Pakistan, P. 66

36- Diwan-E- Abi Qais Bin Al Aslat, P.86 
3: لان الضلال بعل الحقلا يهك. ـ كها أبسط كلامه حول ذات الله تعالى كنالكبّّ كلامه حول قلقرة الله

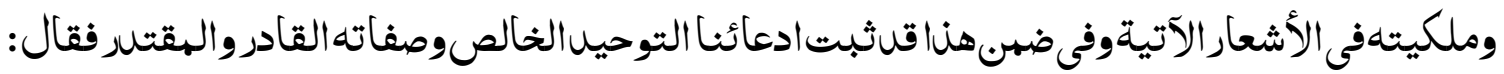

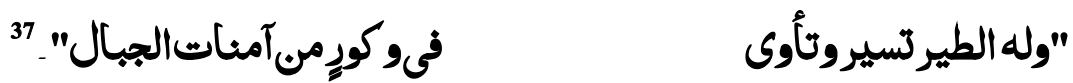

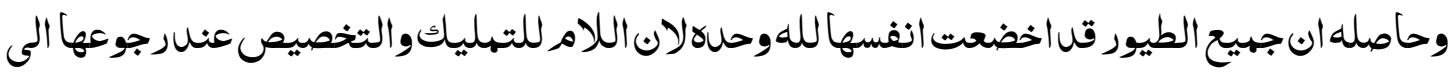

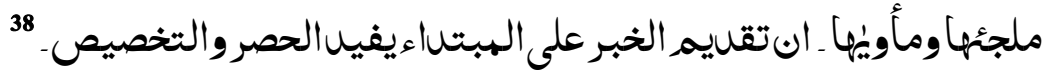

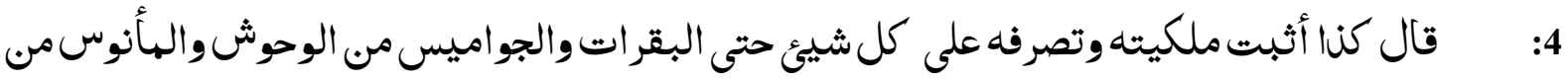
الحيوانات والحشرات كهاجآءبكنا

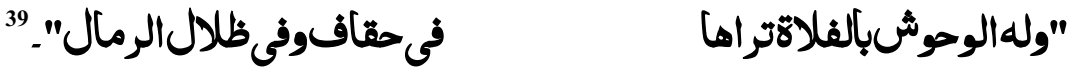

لقuوجل فيه تصور ذات الله قادر ا ومتصرفا في كلشيئ حتى فى قطعات الجبال والرمل ـ فهنا أمر كبير

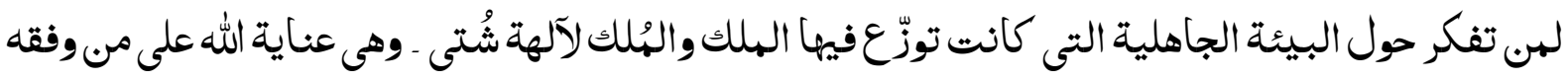
لبيانققلر تها الكاملة الباهر تالغالبة فى هنا الشعر ومابعلهالى الثلاثة|تت تقليمر الخبرللحصروالاختصاص. فخرجتمنها التوحيu الخالصوهوالهر امـ ـ

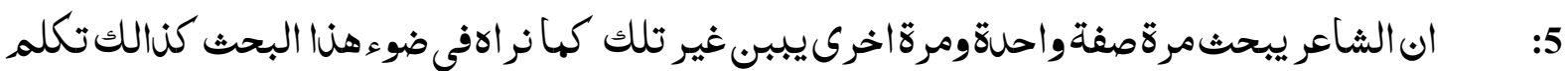
عن صفته تعلى الهعطى كاثف الضرودافح البلاءبحيثقال :

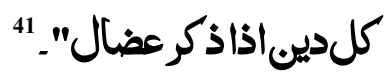
"وله هدّّت بيهودودانت لان الله أعطنى اولادبنى اسر ائيل دين اليهودية وكلها وقعت حادثةفرجعت اليهوهكنا أمرت كل اهل دين اليهعنالفاجعةوالحاجةوالنائبة.

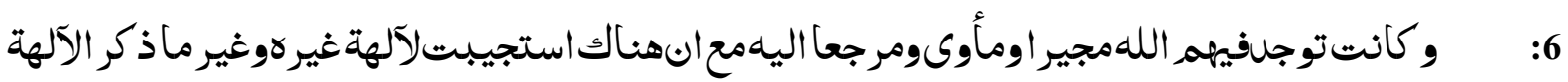

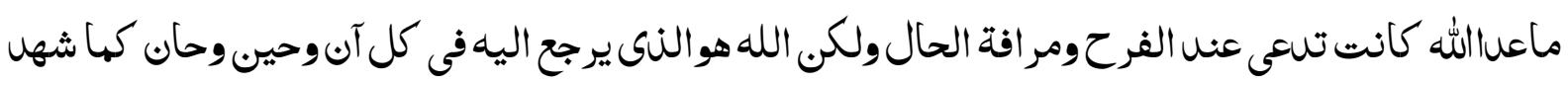

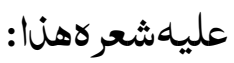

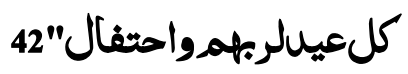

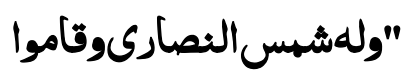

37- Diwan-E- Abi Qais Bin Al Aslat, P.86

38- Abbas Hassan, Al Nahwal Al Wafi, Dar Ul Maarif, Cairo, 2/472

39. Diwan-E- Abi Qais Bin Al Aslat, P.86

40- Ibn Abd Rabbo, Ahmed Bin Muhammad, Al Aqd Al Farid, Vol.3, P. 375

41. Diwan-E- Abi Qais Bin Al Aslat, P.86

42 : Diwan-E- Abi Qais Bin Al Aslat, P.86 


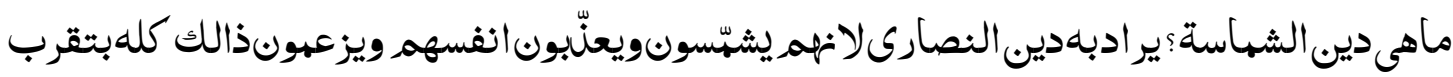

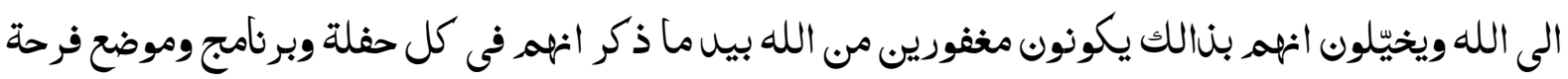
ين كرون اللهويكبرونهوينجلونه.

وليس الغرض منه انهم ما كانوا يفعلون أَ كان صحيحاً امـ لاء ولكى الهقصود منهاًن تصورذات الله

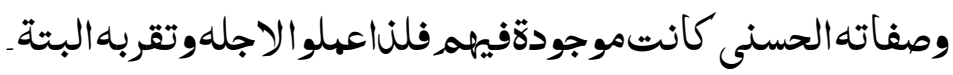

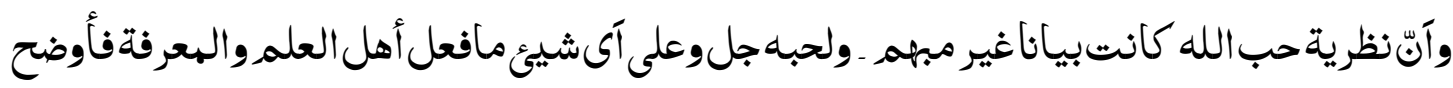
:7 ذالك كنا:

\section{"ولهالراهب الحبيستراه}

يعنياِن النين تركو النيا وأسروا أنفسهم في صومعة وكنيسة ما ومافعلوا ذلك إلاً ابتغاء وجه الله ورضائه. فكم من ترى فقيرًا ومسكينا ومحتاجا ما كانوا على تلك الحالة بلهم على عيش غلقفتركو اذالككله

للهوحلاكوافتخرواعلى ذالك كهاقال رحة اللعالهين صلى الله عليهوسله :"الفقرفخرى". 44

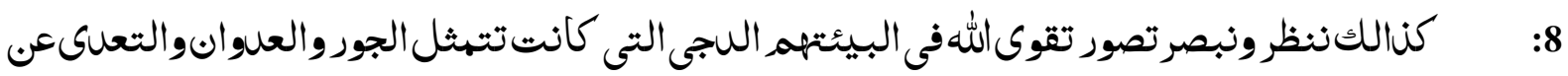

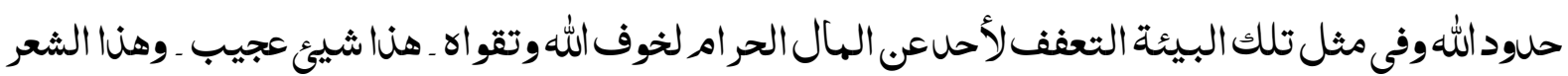

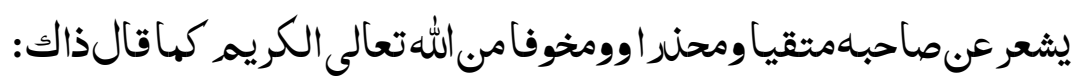

ربنايستحلغير الحلال" 45 "واتقوا اللهفى ضعفاف اليتامئ

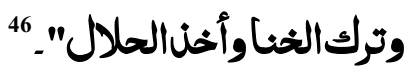

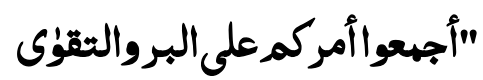

يكفى لنا ان نقر أذهنه الخصبة حول تقوى الله فى الهعاملات مى الكلاه الهن كورة فهى: يا يها الأولاد؛

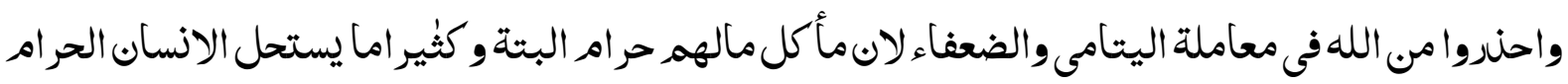
ثمياكله ولكن لاتفعلوا ذالك. وعليكم الاتفاق فى امور مختلفة- واياكم والتفريق- البر ایى حسب الهعاملة والتقوى وهكنا كونو اوحلاناعلى تركفحشة الكلامرولاتقصروافى كسب الحلال وأخنهاو كله.

43. Diwan-E- Abi Qais Bin Al Aslat, P.86

44. Mulla Ali Al Qari, Abu Al Hassan Ali Bin Muhammad, Marqat Al Maftahah, Dar Al Fikr, Beirut, 2002, 9/433

45: Diwan-E- Abi Qais Bin Al Aslat, P.86

46- Diwan-E- Abi Qais Bin Al Aslat, P.87 


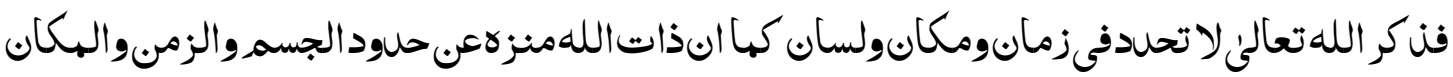
كنالكذ كرهالعالىسُبحانمـذالك.

وإن نشاء ملخص الأشعار مى قوله سبحوالله الى هنا الشعر فنقول ان في الشعر الاول جيئ السعوى

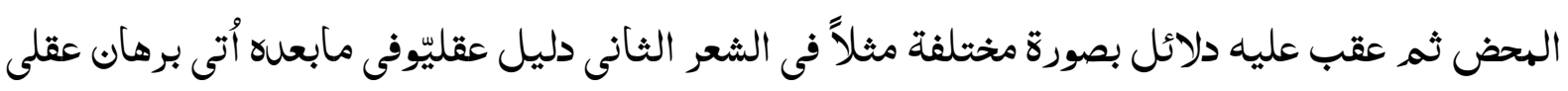

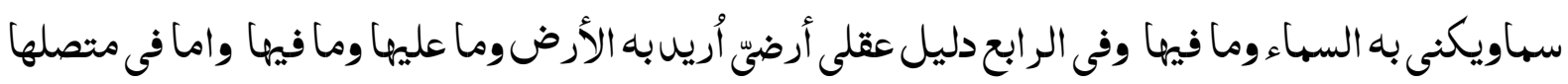

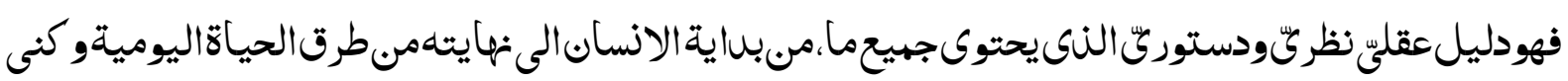

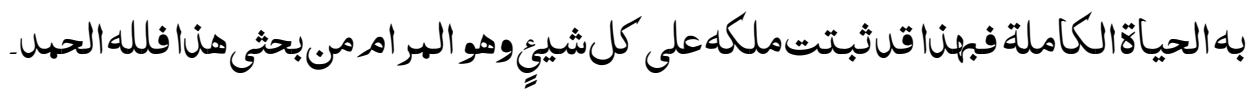
أشعاركافى التوحيلبالهتطلبات الصفات:

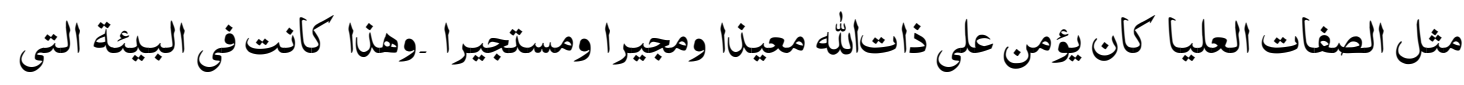

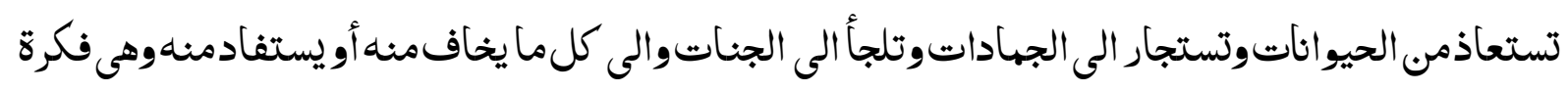

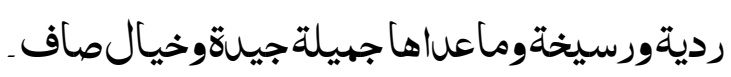
1 إبينها الشاعر الهن كوربقوله:

وشرّزباغيكمودسّالعقارب".

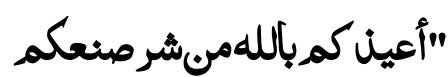

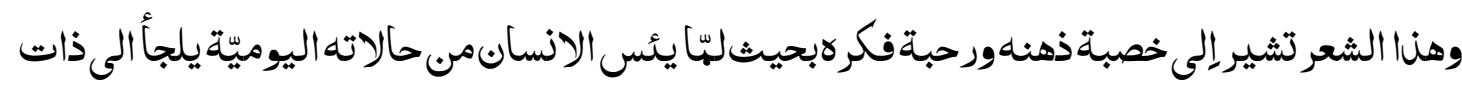
يطهئبدةقلبه. والنات ذوالهأوئ والهلجائ تكون متنوّّة وفق البيئة ، النهن والفكر ولكن شاعرنأ هنا . وان كان من

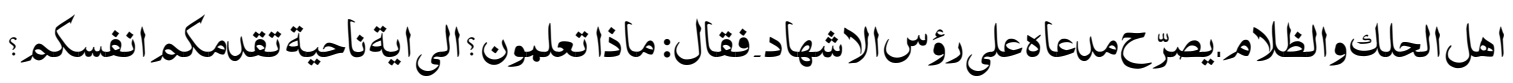

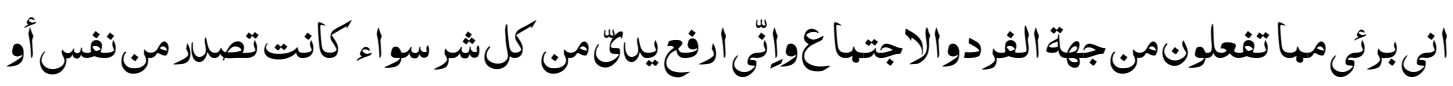
نفوِّلان" الشر "مصلر وهوإذا يطلنير ادبهالفرد الكامل والعامـ. 48 فإذا هو يشتهل جهيح انواع الثر من الفستقوالفجور والعصيان والظلمـ والجور والكبر والرياء والسمعة والشهرةوالنفاقوالقتال وغيرها ـ.

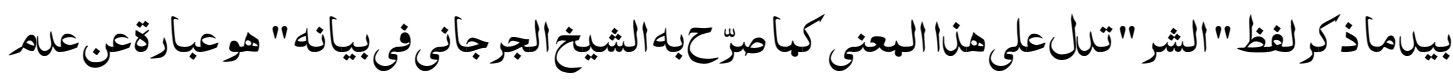

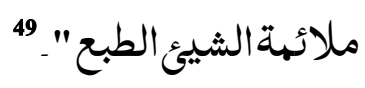

47- Diwan-E- Abi Qais Bin Al Aslat, P.65

48- Al Suyuti, Jalal Al Din, Hammam Al Hamawa, Sharha Jama’ ul Jaami’, Dar Ul Bahoos Al Alamia, Beirut, $1989,5 / 76$

49. Al Jurjani, Al Sayyid Sharif,Al Tarifaat, P. 91 


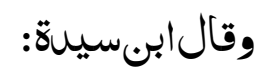

"هوضلالخيرومايرغبعنها العقلاءوذو الفطرةالسليهة "ـ

يفهم منه ان المحاشرة والبيئة كانت إمتلأت مث الشر الانفر ادية والاجتهاعيةوفيهنه الحالة لا حول

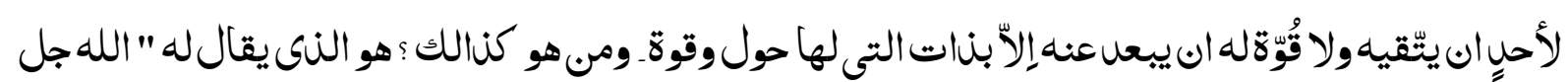
جلاله" النىى اذبهالشاعرفقال:

وأنأرجوالى اللهالكريموحسه" "أنأستعينبهوأنأنبرّكُكبه

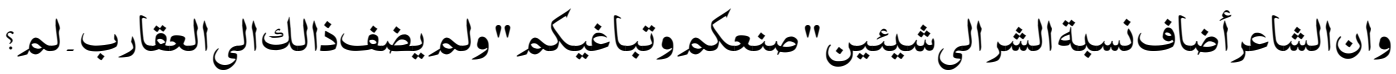
لان العهل القبيح والعهل الشر ليست من فطرة الانسان لان فطرته هو الايهان على لله وحله والعهل الصالح -و كلما يعهل بخلافهفهوشر -

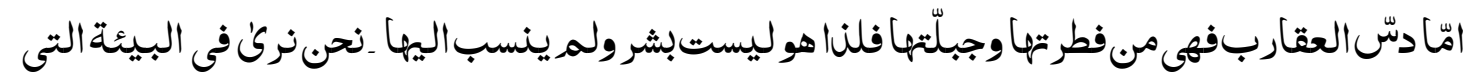
كل شيئ يتوجه الى غير الله وكثرت فيها أعساءالله و كونو احل منها يسعو الى عبادة الاصناه ولكن هناك رجل

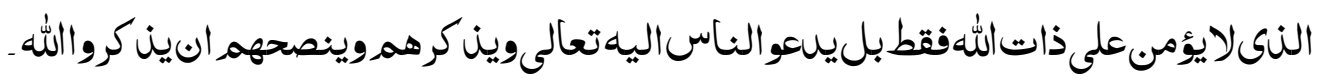

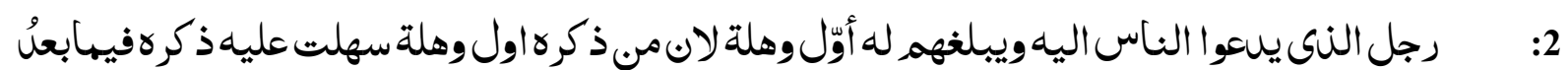
فأوضحذالك:

\section{"فنكرهم بالللهاوّل}

وهنه مرتبة كبيرة لها ان ارسال الرسالة وبعث السفير والقاصل لسعوة الله من الأمور الهفتخرة

والمهتهة.

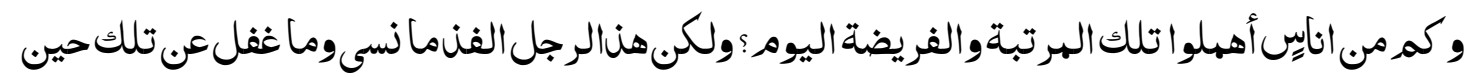
ما كادت تشب النار بين الرسول صلى الله عليه وسلمـوقومهوبينهوبين أعساء رسالته ـ أرسل ابوقيس رسالة مناكورةالى القريشردالهمرفقال:

$$
\text { عليكم بن كر اللهلان الامرياتى للزجر أيضًا. }
$$

ولفظ " ذكر" يتوجهنا الى عهت معنيه ووسعة بحرله لم ؟لان الن كر لفظ عام تحيط بجهيح أنواع النكر ،الن كر اللسانىوالقلبىوالعلى، النكر الانفر ادىوالاجتهاعى، الن كر الخفىوالجلى، الن كر بالهال والهقال ـ واول 
وهلة اىقبل كل عملوفعل اذكرواللهلان النكردواء لكلداء ـ وبساية العهلبغيرذكر اللهيكون اقطع وابتر كها فى" كل كلاه أو أمرذى بال لايفتحبناكر اللهفهو ابتر اوقال أقطع" . 52

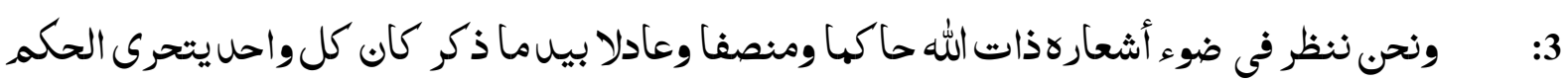
والعلفأظهر رأيهفيه كنالك:

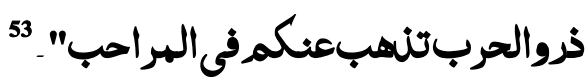
"وقل لهمرواللهيحكمحكه" وفى اثناءذالكيبيندراسة التو كلعلى الله الكبير فظهر منهصفتها المتوكل على الله.

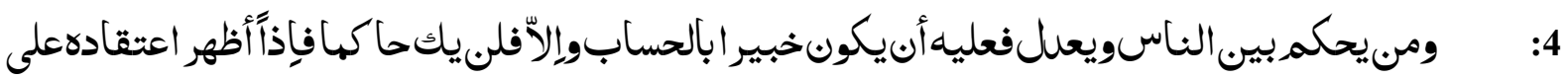
اللهحا كها ومنصفا كها ابرز ايهانهعليهمحاسبابقوله:

حسابكمواللهخيرمحاسب". "فيعوا الحربملهحاربواذكروا"

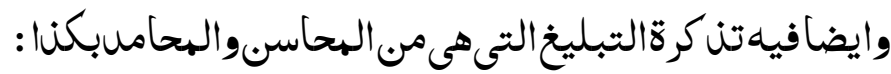

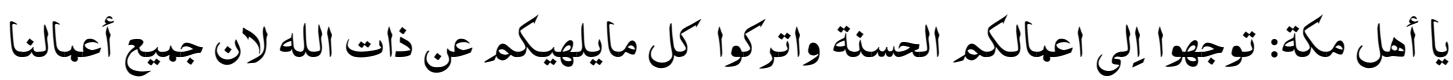

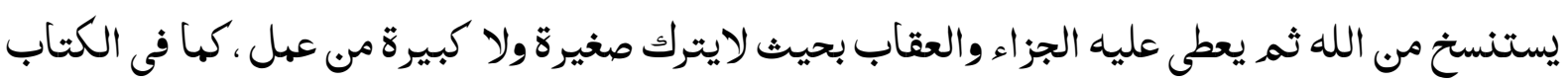
العزيز"لايغادر صغيرةولا كبيرة".. 55 ومح الرغم هنا قنا تضحت انهكان يؤمن على ذات اللهكونه حفيظاً وعليهاً باقتضاء النص لان الحساب

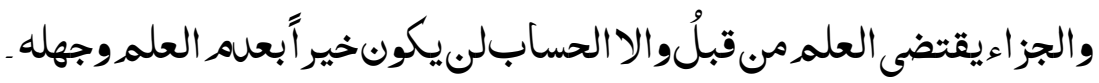

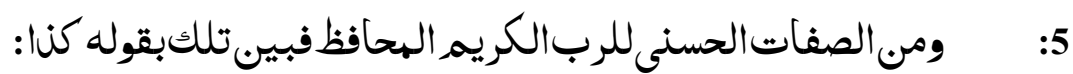

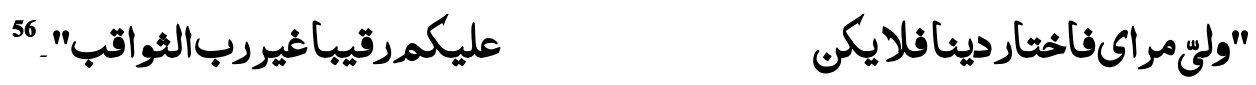
انهآمن على توحيuاللهووحلانيتهبل كانبيبلخ ذالكايضاً إمثل كنا:

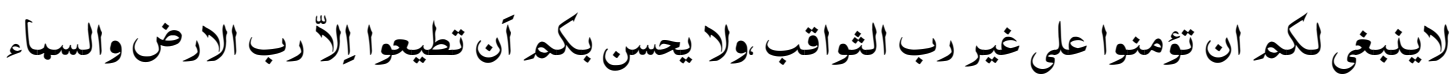

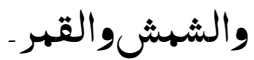

52- Nasa'i, Ahmad Bin Shuaib (215-303AH/830.915AH). Al Sunan. Beirut, Labnon: Dar Al Kutub Al Ilmia, 1416 AH / 1995 - Hadith No.: 2315

53- Diwan-E- Abi Qais Bin Al Aslat, P.65

54- Diwan-E- Abi Qais Bin Al Aslat, P.68

55- Al Kahaf: 18/49

56- Diwan-E- Abi Qais Bin Al Aslat, P.68 
لئن ننظر اليهمنحيث السعوىوالسليل يتضحعلينا ان الشطر الثانى دعوى أى لارقيبولا محافظولا

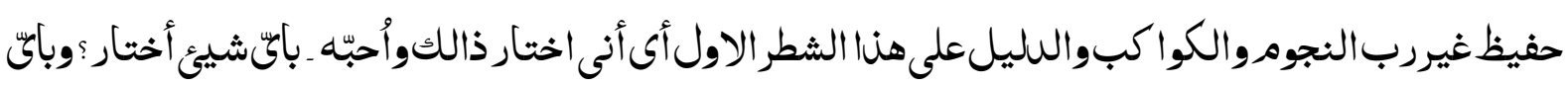

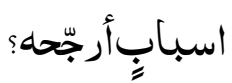

فجوابهسهلوواضح انهاستعهل ذهنهوفكر كوتفكرفى ذالك. ومنيتفكر اويتلبر كنالكيجلنّ اللهوحيuاوواحساً.

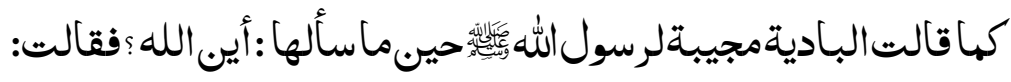

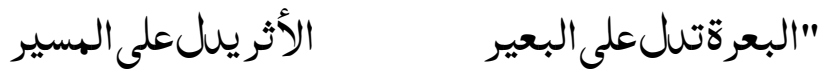

$$
\begin{aligned}
& \text { فسهأءذاتأبراج }
\end{aligned}
$$

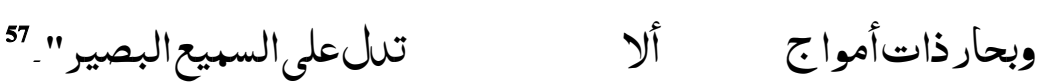

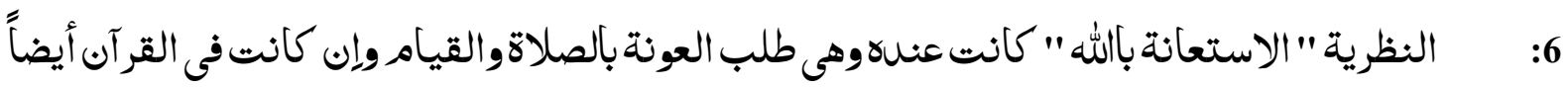
ولكن توجلفى العربقبل الإسلاه كهاذ كرها فى النيل

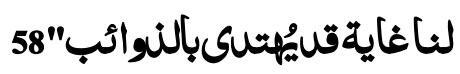

باركانهنا البيتبين الاخاشب"

\section{"أقيهوالناديناحنيفاً فأنتم}

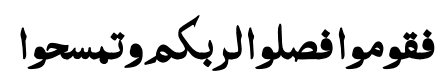

انهما قuآمن على الله وحلهبل كان يتهناهم. اهل مكة ويطالب منهم انهم يكونون حنفآيلِله وأولياء

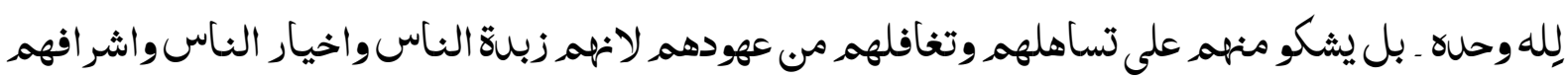
والناسعلى دين أشر افهم وملو كهم فلناقال متأسفا عليهم مثل كنالك: يأهل مكة : ايّاكم والحنر عن التساهل والتغافل واتركوا اعهالكم اليومية السنيئة بل عليكم القياه.

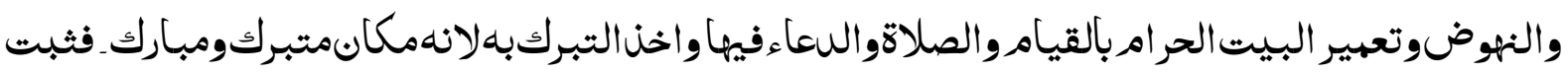
مثلهفةمتعلقه كعبة اللها الهكرمة.

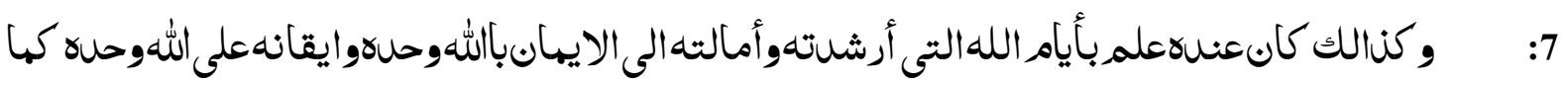
صرحذالك:

جنودالهليكبينسافوحاصب" 60 1"فلأناكمنصرذى العرشردهم انه لم يكتف على الأقوال الهحضة والسعوة الى الله بلسانه فقط بل وضح أمامهم عهل الله ونصرته

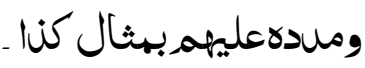

57- Al Jauzi, Jamal ul Din, Zad Al Masir fi Ilm Tafsir, Dar Al Kitab Al Arabi, Beirut, 1/362

58: Diwan-E- Abi Qais Bin Al Aslat, P.68

59. Diwan-E- Abi Qais Bin Al Aslat, P.69

60- Diwan-E- Abi Qais Bin Al Aslat, P.69 
لها حمل وصال على الكعبة الهكرمة أبرهة وأصحابه ذوالفيل فأطردهم الله ملاحوراً وأرسل عليهم.

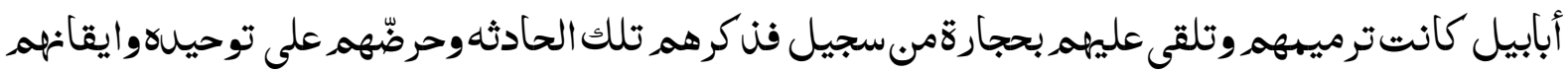
عليه.

$$
\begin{aligned}
& \text { فقال:فلهآآتاكم الخ لقلثبتتبمنهاشياءمتنوعةحسبمايلى: } \\
& \text { 1) }
\end{aligned}
$$

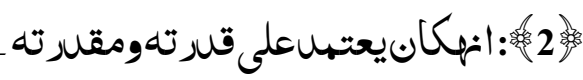

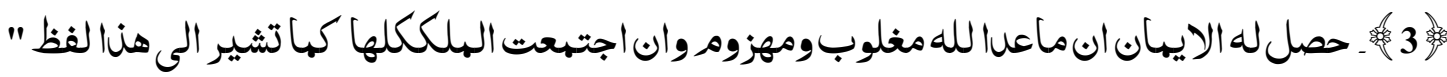

$$
\text { جنود"بصورةالجهح- }
$$

4)

$$
\text { العربإستخلامها". }
$$

8: ومن صفاتهالعليا الهجزءوهو كانبيتيقنعليهقائلاً:

وعناللهصالحمأنيت

وقومى كلذظلكم كفيت".

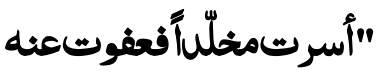

\section{مزينةعندويهودقرىى}

يفهم منهعقيسته حول"جزاء اللهوثوابه"على العهل الصالحوالعقاب على العهل السيئة ـفلنا لها أسر مخلسا بـ الصامت الساعلى يوم بعاث النى كان قائسا في هنه الحرب فأطلقه وخليّ سبيله مع منح قومه اياهاه

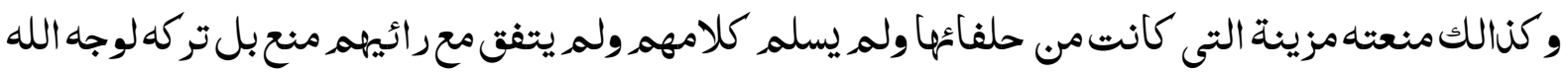
ورضائه.

$$
\begin{aligned}
& \text { فثبتمنهبuاهة انتصورهكانتمربوطةبنات اللهوصفاتهومتعلقاتصفاته . } \\
& \text { وفىروايةجائت "أجرت"محل" أسرت". } 63
\end{aligned}
$$

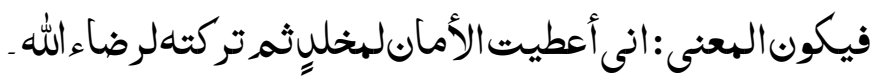

$$
\begin{aligned}
& 5
\end{aligned}
$$

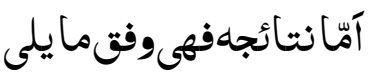

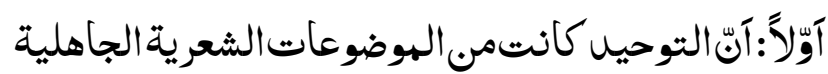

$$
\begin{aligned}
& \text { ثأنياً: أبوقيسبن الأسلت الأوسى كانبمى الحنفآء }
\end{aligned}
$$

61- Ahmed Mukhtar Omar, Majam Ul Lughat Al Arabia Al Muasirah, Maktaba Aalam Al Kitab, Cairo, 1/362

62. Diwan of Abi Qais Bin Al Aslat, P. 71

63. Diwan-E- Abi Qais Bin Al Aslat, P.72 


$$
\begin{aligned}
& \text { ثأثاً: أثَّعلهه حول الهوضوعات الينية كانتذذارحبةومتسعة }
\end{aligned}
$$

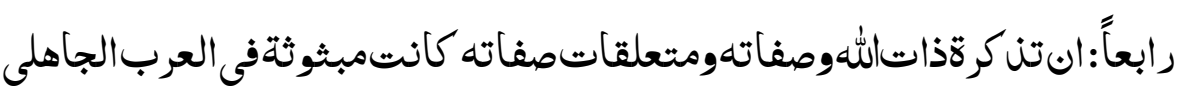

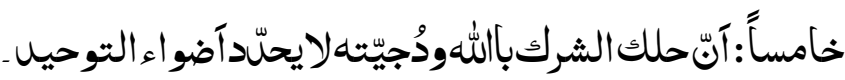

(c) (7) (2) This work is licensed under an Attribution-ShareAlike 4.0 International (CC BY-SA 4.0) 